IZA DP No. 7951

Tuition Fees as a Commitment Device

Nadine Ketel

Jona Linde

Hessel Oosterbeek

Bas van der Klaauw

February 2014 


\title{
Tuition Fees as a Commitment Device
}

\author{
Nadine Ketel \\ VU University Amsterdam, \\ University of Amsterdam and Tinbergen Institute \\ Jona Linde \\ VU University Amsterdam \\ and Tinbergen Institute \\ Hessel Oosterbeek \\ University of Amsterdam \\ and TIER \\ Bas van der Klaauw \\ VU University Amsterdam, \\ Tinbergen Institute, CEPR and IZA
}

Discussion Paper No. 7951

February 2014

\author{
IZA \\ P.O. Box 7240 \\ 53072 Bonn \\ Germany \\ Phone: +49-228-3894-0 \\ Fax: +49-228-3894-180 \\ E-mail: iza@iza.org
}

Any opinions expressed here are those of the author(s) and not those of IZA. Research published in this series may include views on policy, but the institute itself takes no institutional policy positions. The IZA research network is committed to the IZA Guiding Principles of Research Integrity.

The Institute for the Study of Labor (IZA) in Bonn is a local and virtual international research center and a place of communication between science, politics and business. IZA is an independent nonprofit organization supported by Deutsche Post Foundation. The center is associated with the University of Bonn and offers a stimulating research environment through its international network, workshops and conferences, data service, project support, research visits and doctoral program. IZA engages in (i) original and internationally competitive research in all fields of labor economics, (ii) development of policy concepts, and (iii) dissemination of research results and concepts to the interested public.

IZA Discussion Papers often represent preliminary work and are circulated to encourage discussion. Citation of such a paper should account for its provisional character. A revised version may be available directly from the author. 
IZA Discussion Paper No. 7951

February 2014

\section{ABSTRACT}

\section{Tuition Fees as a Commitment Device*}

This paper reports on a field experiment testing for sunk-cost effects in an education setting. Students signing up for extra-curricular tutorial sessions randomly received a discount on the tuition fee. The sunk-cost effect predicts that students who receive larger discounts will attend fewer tutorial sessions. For the full sample, we find little support for this hypothesis, but we find a significant effect of sunk costs on attendance for the $45 \%$ of students in our sample who are categorized as sunk-cost prone based on hypothetical survey questions. For them higher tuition fees can serve as a commitment device to attend classes.

JEL Classification: C93, D03, I22

Keywords: sunk-cost effect, higher education, field experiment

Corresponding author:

Bas van der Klaauw

Department of Economics

VU University Amsterdam

De Boelelaan 1105

1081 HV Amsterdam

The Netherlands

E-mail: b.vander.klaauw@vu.nl

\footnotetext{
* We gratefully acknowledge valuable comments from seminar participants at various places. We thank de Bijlespartner and the instructors of the tutorials for their cooperation. We appreciate financial support from the University of Amsterdam through the Speerpunt Behavioral Economics.
} 


\section{Introduction}

Education is heavily subsidized around the world. These subsidies can lower student effort and performance through two channels. First, higher subsidies attract more students and these additional students may be weaker or less motivated than the average student. ${ }^{1}$ Second, higher subsidies may - net of selection - reduce student effort through a sunk-cost effect (Thaler, 1980; Arkes and Blumer, 1985). Students who pay less for their study sink a lower cost, and may feel less committed than students who pay the full price. In this paper we present the results of a field experiment which examines this second channel. ${ }^{2}$

We run a field experiment in which we randomly subsidize Dutch university students who have signed up for a course of extra-curricular tutorial sessions. When participants come to pay the offer price, they may randomly receive an unexpected discount. As a result treated and control participants have, on average, the same willingness to pay, but the actual transaction prices they paid differ. The size of the discount is determined by randomly picking a closed envelope, so participants have no reason to believe that the discount is related to the quality of the course.

There is surprisingly little solid empirical evidence in favor or against the sunk-cost bias. For a long time only Arkes and Blumer (1985) provided evidence. They demonstrate the sunk-cost effect by randomly providing theater patrons with a discount. Participants who received a discount visited the theater significantly less often. This is, however, only the case for the first half of the theater season; in the second half differences between the discount and the no-discount group are no longer significant. ${ }^{3}$

Three recent studies investigate the sunk-cost effect in field experiments in developing countries. Ashraf et al. (2010) conducted an experiment in a door-to-door sale of a water purification product to about 1,000 households in Zambia. To disentangle selection effects from the effect of sunk costs, they use a clever two-stage pricing design. In the first stage, participating households were offered the product for a one-time only randomly chosen offer price. In the second stage, households that agreed to purchase received an unanticipated

\footnotetext{
${ }^{1}$ Studies showing that lower tuition fees or more financial aid increase enrollment include Van der Klaauw (2002), Kane (2003) and Dynarski (2003).

${ }^{2} \mathrm{~A}$ third channel, potentially operating in the opposite direction, is an income effect. Students who pay the full price have reduced wealth, and may, therefore, work more and "consume" fewer tutorial sessions. We assess the importance of income effects for our study in Section 4.

${ }^{3}$ The sunk-cost bias has also been investigated in laboratory experiments. Phillips et al. (1991) report that some participants exhibit the sunk-cost effect when they value lottery tickets, while others experience the reverse effect. Friedman et al. (2007) find a small sunk-cost bias in a search task, but the results are very sensitive to the details of the task. Offerman and Potters (2006) show that higher entry fees facilitate cooperation and Meyer (1993) that higher entree fees increase bids in an auction.
} 
randomly chosen discount. Two weeks later data were collected concerning usage of the product. The study finds no evidence that households that pay a higher transaction price are more likely to use the product. If, however, paying something is compared to paying nothing, point estimates are consistent with the sunk-cost effect, but not significant.

Cohen and Dupas (2010) use a similar two-stage design to estimate the impact of the price paid on the use of antimalarial insecticide-treated bed nets offered by prenatal clinics to pregnant women in Kenya. They also fail to find a significant sunk-cost effect. The point estimates are negative, even when paying something is compared to paying nothing. Finally, Hidalgo et al. (2013) report about an experiment where free school uniforms were provided to primary school children in deprived areas in Ecuador. To minimize selection effects, the provision of free uniforms to treatment schools was not publicly announced and the analysis focuses on students in the last two years of primary school. This study finds a significantly negative effect of free provision of uniforms on school attendance measured during three unannounced visits, which is consistent with the sunk-cost effect. A possible explanation for why Hidalgo et al. (2013) find a sunk-cost effect while Ashraf et al. (2010) and Cohen and Dupas (2010) do not, is the difference in prices between products (cf. Garland and Newport, 1991; Rodrik, 2009). While participants in the experiments in Zambia and Kenya pay less than one US\$ for the water purification product or the bed net, parents in Ecuador would otherwise spend close to 25 US\$ on their child's school uniform.

The design of our study is similar to the second stage of the two-stage pricing design used by Ashraf et al. (2010) and Cohen and Dupas (2010). Conditional on participants' willingness to pay the full price they receive an unanticipated randomly chosen discount. But, to give the sunk-cost effect a better chance, the absolute amounts of the discounts in our experiment are large (up to $€ 75$ ). Compared to the study of Hidalgo et al. (2013), we distinguish four price levels instead of only two, and we obtain much richer background information of participants. In particular, a hypothetical survey question allows us to identify students who are sunk-cost prone, which is almost half of the total sample.

The main result of this paper is that we find a significant effect of sunk costs on attendance (but not on performance) for the $45 \%$ students in our sample who are categorized as sunk-cost prone based on hypothetical survey questions. For the full sample of students, we find little support for such an effect. If our results carry over from the specific context of extra-curricular classes to the context of regular classes, we have identified a way to increase students' attendance. This is important in light of the serious concerns of policy makers in the Netherlands (and elsewhere) about the low effort that university students devote to their studies. 
The remainder of this paper is structured as follows, Section 2 describes the setting of our study, the experimental design and the data. Section 3 briefly discusses our empirical approach. Section 4 presents and discusses the results. Section 5 summarizes and concludes.

\section{Design and data}

\subsection{Setting}

Our field experiment concerns students participating in additional tutorial sessions for various courses at four Dutch universities. These sessions are offered by De Bijlespartner, a company organizing additional tutorial sessions for students in cooperation with several local study associations. This company provides study materials and recruits more senior students, who performed well on the subject, as teachers. Each tutorial group contains between eight and 13 students. Tutorial sessions are connected to a course offered in the regular curriculum and these sessions run concurrently with that course. Courses at Dutch universities typically last seven or eight weeks, the tutorial sessions take place during the final four or five weeks. ${ }^{4}$ Each week there is one tutorial session of two or three hours. Students register online through their study association's website for the tutorial sessions. At the start of the first session, participants pay for the full set of four or five sessions. The listed price for a set of tutorial sessions varies somewhat between courses and is either $€ 60, € 65$ or $€ 75$. The prices are not affected by our experiment; the company offers similar tutorials for the same prices in other periods during the academic year.

The experiment involved five study programs at four Dutch universities: business administration and psychology at the VU University Amsterdam, economics and business at the University of Amsterdam, social sciences at Utrecht University, and psychology at the University of Groningen. For each study program we carried out the experiment only during one block of courses to prevent that students would expect to get a discount. In total, we included tutorial sessions for 14 courses in our experiment. All courses are offered under the name of the student association of the study program (not under the name of the company) which ensures that students would not expect a discount when hearing about discounts in other study programs. The courses for which the tutorial sessions are offered are mainly statistics or math courses because students find these courses particularly difficult. Table A1 in Appendix A lists for each study program the courses for which tutorial sessions were offered, the full

\footnotetext{
${ }^{4}$ The tutorial sessions start later than the course so that students can decide in the first weeks whether or not to take the additional tutorial sessions.
} 
price, and the numbers of groups and participating students.

\subsection{Experimental design}

The goal of our field experiment is to study whether education subsidies affect study effort and performance in isolation from the enrollment decision. In particular, we aim to test for the presence of a sunk-cost effect. To generate variation in tuition fees independent of students' willingness to pay, we randomly gave an unexpected discount to students who already signed up and were ready to pay the full tuition fee. We introduced four possible discounts: a full discount (treatment Free), a discount of the full price minus $€ 10$ (treatment Large Discount; LD), a discount of $€ 10$ (treatment Small Discount; SD) and no discount (treatment Full Price). All students have an equal ex ante probability to receive each discount level.

For the experiment we took control of the payment process for the tutorial sessions. When students registered for a set of tutorial sessions, they were informed that they had to pay in cash at the start of the first session. When students arrived we invited them to participate in a study on study behavior and informed them that they could get a discount. Students were not informed about the goal of our study and were not told why randomly different discounts were offered. Upon agreeing to participate students completed a questionnaire in which they also gave permission to use their information for this study. ${ }^{5}$ The questionnaire asked, for example, about study habits, maximum willingness to pay and how much they thought the tutorial would help them to pass the relevant exam. An English translation of this pre-treatment questionnaire is in Appendix B.

After completing the questionnaire students entered a classroom one at a time to determine their discount and pay the remaining tuition fee. They were told that they had an equal chance to receive any of the four possible discounts, and that the discount would be determined by choosing a closed envelope. Before arrival of the students we prepared the envelopes with discount tickets, including an equal number of envelopes for each discount. When a student picked an envelope, this envelope was not replaced. The number of envelopes was such that the final student could choose from at least four envelopes. We chose this procedure because it is very clear to participants that the discount is randomly determined and unrelated to the quality of the tutorial sessions. This avoids that students infer something about the quality of the course from the transaction price they paid. We asked students not to reveal their discount when leaving the room to prevent students who had not paid yet from

\footnotetext{
${ }^{5}$ Only two out of 373 students refused to participate and they paid the full price. Students who did not show up for the first session or registered for the tutorial session after the official deadline were not allowed to participate in our experiment.
} 
updating probabilities for specific discounts.

During the course the teachers recorded students' attendance at each session and reported this to us after the course. During the final tutorial session students filled out the usual evaluation form to which we added some questions. These questions included a control question to check whether students remembered their discount, their opinion about the discount and hypothetical sunk-cost questions. An English translation of the post-treatment questionnaire can be found in Appendix B. If students were not present at the final session we contacted them to complete the evaluation form either through email or over the phone. The response rate is $94 \%$. Finally, from the university administrations we received grades for the exams of the regular course connected to the tutorial sessions.

A possible contaminator to the sunk-cost effect is the income effect operating in the opposite direction. We asked students whether they paid for the tutorial sessions themselves or whether they received extra money from others, for example,their parents. We also asked students about their monthly income. The income effect may be less important for students whose parents pay for the course and for students with a relatively high income.

Following Ashraf et al. (2010) we included hypothetical sunk-cost questions in the posttreatment survey, which allows us to identify sunk-cost-prone people. We asked participants "suppose you bought a bottle of juice for $€ 2$. When you start to drink it, you realize you don't really like the taste. Would you finish drinking it?" Next, we asked two follow-up questions, for $€ 5$ and $€ 1$, "Now suppose you bought exactly the same bottle of juice for $€$.. . Would you finish drinking it?". A participant is categorized as sunk-cost prone if s/he always finishes the bottle, or finishes the bottle when a high price has been paid and doesn't finish the bottle when a lower price has been paid.

\subsection{Data}

In total, 371 students registered before the official deadline and showed up for the first meeting. Some students took two or three different tutorial courses at the same time and could get a discount at each occasion. The sample of 371 observations consists of 340 unique students, participating in 14 different subjects and 39 different tutorial groups. Randomization of the discounts took place within each tutorial group. From our sample we exclude students who are older than 26 or earn more than $€ 1200$ a month, because they are often part-time students. We also exclude two students without exam information. The final sample contains 339 observations (312 unique students).

Table 1 provides descriptive statistics for the full sample and for each treatment group 
Table 1. Descriptive statistics

\begin{tabular}{|c|c|c|c|c|c|c|c|}
\hline & \multirow[b]{2}{*}{ obs } & \multirow[b]{2}{*}{ All } & \multicolumn{4}{|c|}{ Treatment } & \multirow[b]{2}{*}{ p-value } \\
\hline & & & Free & LD & $\mathrm{SD}$ & Full price & \\
\hline \multicolumn{8}{|l|}{ Pre-treatment survey } \\
\hline Female & 339 & 0.61 & 0.62 & 0.57 & 0.64 & 0.62 & 0.87 \\
\hline Age & 338 & 21.1 & 20.8 & 21.5 & 21.0 & 21.3 & 0.23 \\
\hline Monthly income (in $€$ ) & 335 & 567 & 532 & 528 & 573 & 631 & 0.05 \\
\hline Economics or Business student & 339 & 0.60 & 0.60 & 0.65 & 0.62 & 0.55 & 0.76 \\
\hline Time spend on study (per week) & 338 & 27.0 & 26.9 & 27.5 & 27.2 & 26.4 & 0.87 \\
\hline Time spend on subject (predicted) & 337 & 13.3 & 14.5 & 12.5 & 12.7 & 13.3 & 0.79 \\
\hline First attempt for exam & 337 & 0.68 & 0.67 & 0.65 & 0.65 & 0.75 & 0.63 \\
\hline Max. willingness to pay (fraction of price) & 333 & 1.12 & 1.12 & 1.11 & 1.11 & 1.13 & 0.55 \\
\hline Predicted prob. passing without tutorial & 338 & 0.45 & 0.45 & 0.44 & 0.44 & 0.48 & 0.14 \\
\hline Predicted prob. passing with tutorial & 338 & 0.73 & 0.73 & 0.72 & 0.70 & 0.75 & 0.12 \\
\hline Course payed by parents & 339 & 0.49 & 0.51 & 0.44 & 0.54 & 0.45 & 0.63 \\
\hline \multicolumn{8}{|l|}{ Post-treatment survey } \\
\hline Sunk-costs prone & 306 & 0.45 & 0.50 & 0.44 & 0.45 & 0.42 & 0.86 \\
\hline Quality of the course (scale 1-10) & 319 & 7.19 & 7.26 & 7.45 & 7.04 & 7.04 & 0.46 \\
\hline Hour spent on course & 317 & 10.8 & 11.1 & 10.9 & 10.5 & 10.8 & 0.74 \\
\hline Subjective probability of passing exam & 316 & 0.62 & 0.62 & 0.63 & 0.62 & 0.63 & 0.71 \\
\hline$\geqq 1$ of controls missing & 339 & 0.03 & 0.02 & 0.03 & 0.06 & 0.03 & 0.98 \\
\hline Total number of observations & & 339 & 86 & 79 & 87 & 87 & \\
\hline
\end{tabular}

Note: The final column present the p-value of a Kruskal-Wallis equality-of-populations rank test.

separately. Due to the $6 \%$ non-response on the post-treatment survey and some item nonresponse, the numbers of observations vary somewhat between variables. Observations are fairly equally divided over the treatment groups. Around $60 \%$ of the participants are female and the average age is 21.1 years. The mean monthly income is about $€ 570$, and it is a bit higher in the groups with a lower discount. About $60 \%$ of the participants are economics students. On average, students report that they devote 27 hours per week to studying and slightly over 13 hours to the course connected to the tutorial sessions. Over $30 \%$ of the students already made at least one attempt to pass the course. Students reported that they were willing to pay, on average, $12 \%$ more for the tutorial sessions than the full price and believe that participation in the sessions raises the likelihood to pass the exam by, on average, 28 percentage points. Almost half of the participants report that they received extra money from their parents to participate in the tutorial sessions. Finally, $45 \%$ of the students should be considered sunk-cost prone according to the hypothetical-choice questions in the questionnaire. 


\section{Empirical strategy}

This section briefly describes our empirical approach. For each outcome (attendance and performance), we present results from the following five regressions:

$$
\begin{aligned}
Y_{i c} & =\alpha_{1}+\beta_{1} \text { Free }_{i}+\eta_{1} L D_{i}+\theta_{1} S D_{i}+\gamma_{1} X_{i}+\mu_{1 c}+\varepsilon_{1 i c} \\
Y_{i c} & =\alpha_{2}+\beta_{2} \text { Free }_{i}+\gamma_{2} X_{i}+\mu_{2 c}+\varepsilon_{2 i c} \\
Y_{i c} & \left.=\alpha_{3}+\beta_{3} \text { Free }_{i}+L D_{i}\right)+\gamma_{3} X_{i}+\mu_{3 c}+\varepsilon_{3 i c} \\
Y_{i c} & \left.=\alpha_{4}+\beta_{4} \text { Free }_{i}+L D_{i}+S D_{i}\right)+\gamma_{4} X_{i}+\mu_{4 c}+\varepsilon_{4 i c} \\
Y_{i c} & =\alpha_{5}+\beta_{5} \text { Discount }_{i}+\gamma_{5} X_{i}+\mu_{5 c}+\varepsilon_{5 i c}
\end{aligned}
$$

where $Y_{i c}$ is the outcome variable for student $i$ in course $c ; F_{r e}, L D_{i}$ and $S D_{i}$ are indicators for the different treatment groups; Discount $_{i}$ is a continuous measure for the discount; $X_{i}$ is a vector of control variables; and the $\mu_{c}$ 's are course fixed effects. The $\beta$ 's, $\eta_{1}$ and $\theta_{1}$ are the parameters of interest.

Equation (1) includes separate dummies for the three different discount levels. This tests for each discount level separately whether it has an impact compared to the "full price". Equation (2) only includes a dummy for the "free" treatment, and, therefore, compares paying nothing to paying something (large discount, small discount and full price jointly). This specification tests whether paying matters. ${ }^{6}$ Equation (3) includes a dummy which equals one for the "free" treatment and the "large discount" treatment, and, therefore, compares these treatments jointly to the other two treatments (small discount and full price) jointly. This specification tests whether paying (almost) nothing has a different impact than paying (almost) the full price and therefore compares two groups of participants with a large price difference between the groups and a small price difference within the groups. Equation (4) includes a dummy which is one if any discount is given and thus compares getting a discount versus paying the full price. Finally, equation (5) includes the size of the discount as fraction of the full price as treatment variable. ${ }^{7}$

\footnotetext{
${ }^{6}$ This specific hypothesis was suggested to Ashraf et al. (2010) by NGO personnel regarding the use of Clorin. They find estimates that are large and positive, but not significant. From which they conclude that "while our data show no evidence of an effect of an act of paying, they are at least consistent with such an effect, suggesting the need for further research."

${ }^{7}$ Note that equations (2) to (5) are restricted versions of equation (1). The respective restrictions are: $(i)$ $\eta_{1}=\theta_{1}=0$; (ii) $\beta_{1}=\eta_{1} ; \theta_{1}=0$; (iii) $\beta_{1}=\eta_{1}=\theta_{1}$; (iv) $\beta_{1}, \eta_{1}$ and $\theta_{1}$ are proportionate to the discounts. Recall that the full price differs somewhat between courses. Therefore, the large and small discount are a slightly different fraction of the full price. The course fixed effects deal with this.
} 
For all five equations we present results from specifications with and without control variables. The control variables are gender, age, income, maximum willingness to pay, whether the course is paid by someone else, average study time, whether it is the first attempt for the exam, and the estimated probability to pass the exam without tutorial. All control variables are measured before the randomization. Standard errors are clustered at the level of the 39 tutorial groups.

We also present results from specifications where the treatment variables are interacted with student characteristics. The first student characteristic for which we investigate interaction effects is the sunk-cost-prone indicator. This allows us to examine whether the hypothetical sunk-cost questions help to identify students who respond (stronger) to discounts. The two other student characteristics that we interact with the treatment variables are: i) an indicator for the course being paid by someone else and ii) an indicator for the student having income above the median. With these two variables we assess the relevance of income effects.

\section{Results}

We present the empirical results in four subsections. In subsection 4.1 we present estimates of the impact of the treatments on various measures of attendance. Next we look at the impact of the treatment on study performance in subsection 4.2. Then we characterize the sunkcost-prone students in subsection 4.3. Finally, in subsection 4.4 we assess the importance of income effects of the discounts.

\subsection{The impact of treatments on attendance}

Table 2 presents estimation results for two measures of attendance as outcome variables: being always present at the tutorial sessions and the fraction of sessions attended. Columns (1), (2), (4), and (5) present average effects for the full sample. Columns (3a), (3b), (6a), and (6b) present results from specifications in which the discount variables are interacted with the indicator for sunk-cost proneness. Based on the specifications with interactions, these columns present impact estimates separately for sunk-cost-prone students and for other (non-sunk-cost-prone) students.

The overall pattern for the full sample is somewhat erratic. The results from equation (1) suggest that students who received the free treatment are present less often than students who paid the full price. At the same time, students who received the large discount are 
present more often and are more likely to be always present than students who paid the full price. These findings are somewhat sensitive to the inclusion of control variables. This nonmonotone pattern is neither consistent with a sunk-cost effect nor with an income effect. The results from equation (2) show that students in the free treatment are less likely to be always present and are present less often than students from the three other treatments together. These results disappear when the students who received the large discount are added to those who received the free treatment (equation (3)). This indicates that the main differences in attendance is between the students in the free treatment and in the large discount treatment. These results do not provide evidence in support of a sunk-cost effect in the full sample on being always present or attendance rates.

The effects of the discounts on the attendance of sunk-cost-prone students provide support for the hypothesis that these students attend the tutorial sessions less often and are less likely to be always present when they receive a (large) discount on the tuition fee. The results from equation (1) show that sunk-cost-prone students are 28 percentage points less likely to attend all sessions when they receive the free treatment compared to paying the full price (column 3a). The fraction of tutorial sessions that they attend is also 11 percentage points lower than that of the sunk-cost-prone students who paid the full price (column 6a). The effects on attendance of receiving the large discount or receiving the small discount are also negative for sunk-cost-prone students, although these are not statistically significant. In the other equations the estimated effects of the treatment for sunk-cost-prone students in columns $3 \mathrm{a}$ and $6 \mathrm{a}$, are (with one exception) all significantly negative: students who received a (larger) discount attended fewer tutorial sessions.

Several studies find that people respond to financial incentives during the so-called hot decision stage shortly after the announcement of a payment scheme, but no longer during the cold decision stage (Gneezy and List, 2006; Leuven et al., 2011). Such a pattern is also present in the study of Arkes and Blumer (1985), who find that the sunk-cost effect is driven by behavior in the first half of the theater season. To inquire whether the sunk-cost effect for sunk-cost-prone students is driven by the hot decision stage, we look at students' attendance in each separate tutorial meeting. In particular, we distinguish between the second meeting, the third meeting and the last (fourth or fifth) meeting. ${ }^{8}$ Because students could only participate in our experiment if they attended the first meeting, there is no variation in the attendance in that meeting.

Table 3 reports the effects of treatments on attendance by session, separately for sunk-

\footnotetext{
${ }^{8}$ One course (11 students) had only three meetings. Attendance of the third meeting of that course is included in the analysis of the third meeting as well as in the analysis of the last meeting.
} 


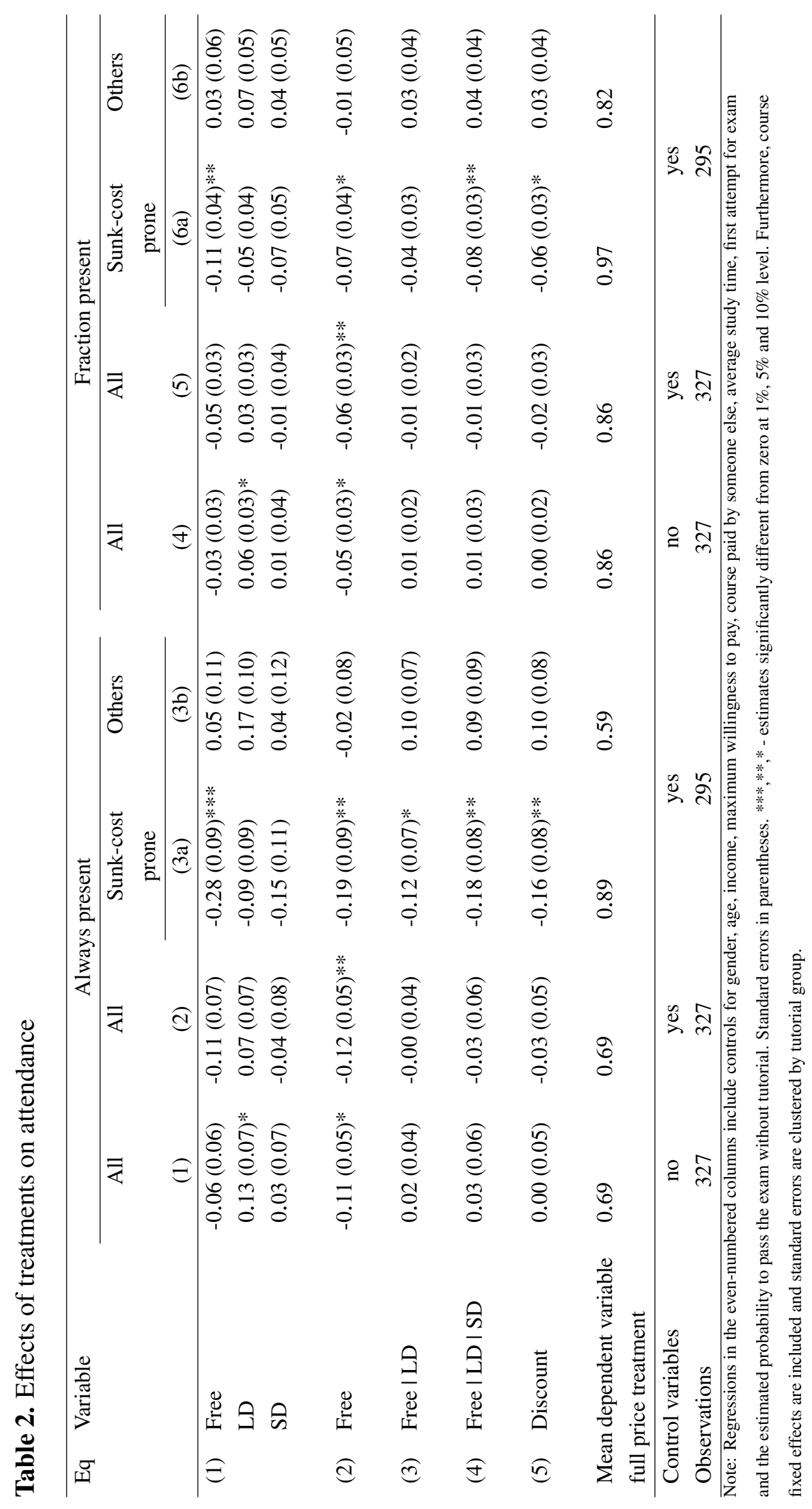


cost-prone students and other students. ${ }^{9}$ For sunk-cost-prone students the effect on attendance is not yet present in the second session. It becomes negative but not significantly so for the third session, and for the last session it is negative and significant. The sunk-cost effect for sunk-cost-prone students is thus not due to the hot decision stage.

\subsection{The impact of treatments on study performance}

We now turn to the impact of the transaction price on study performance. Table 4 reports estimates of the effects of the different treatments on the probability to pass the exam and on the exam grade (conditional on writing the exam). The results are based on regressions that include interactions of the treatment variables and the sunk-cost-prone indicator as well as the full set of control variables. None of the effects of the treatments on exam performance are significantly different from zero, neither for the sunk-cost-prone students nor for the others.

Based on the results in the previous subsection we might have expected that sunk-costprone students perform worse when receiving a larger discount. This is not what we find: their lower attendance does not translate into weaker performance. This is probably due to the fact that the impact of the discounts on attendance is not strong enough. It may also be that the effect of attendance on exam performance is not so strong.

\subsection{Characterizing sunk-cost-prone students}

Only sunk-cost-prone students appear to respond to the discounts. We followed Ashraf et al. (2010) by using hypothetical survey questions to determine the sunk-cost proneness of an individual. Here we characterize sunk-cost-prone students by regressing the indicator for being sunk-cost prone on a number of observed characteristics. Table 5 shows the results from these regressions. Economics and business students are less likely to be sunk-cost prone. This is also true for students who have a high willingness to pay for the tutorial course. Otherwise the results show that the sunk-cost-prone indicator is only weakly correlated with the student characteristics that we observe.

\subsection{Do income effects play a role?}

A discount on the full price may in principle affect attendance through an income effect. Students who pay the full price for the course have less wealth and may, therefore, decide to work more, perhaps at the expense of lower attendance of the course. This mechanism works

\footnotetext{
${ }^{9}$ The results for the full sample show no significant effects of the discounts on attendance by session.
} 


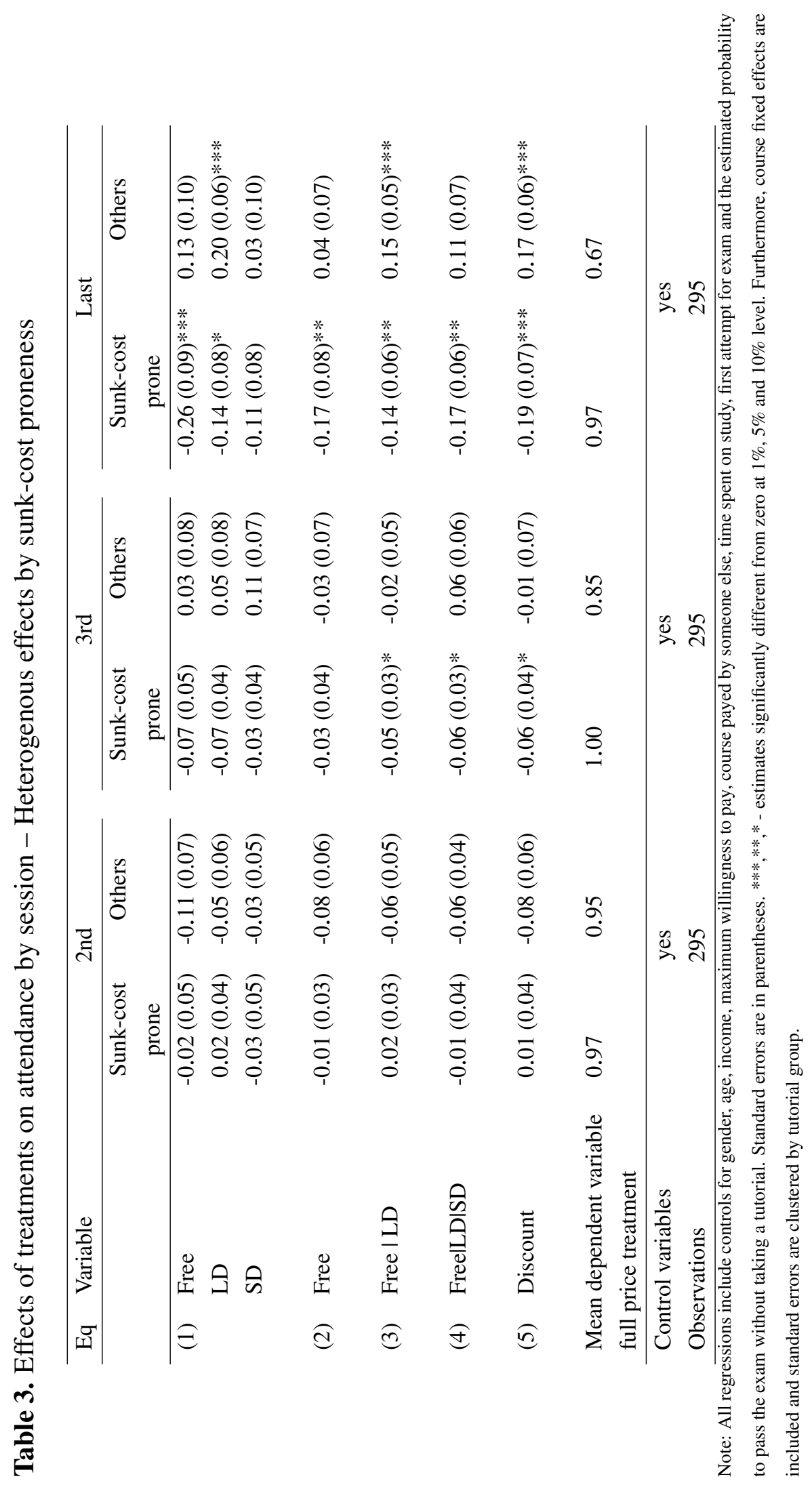


Table 4. Effects of treatments on study performance - Heterogenous effects by sunk-cost proneness

\begin{tabular}{|c|c|c|c|c|c|}
\hline \multirow[t]{2}{*}{$\mathrm{Eq}$} & \multirow[t]{2}{*}{ Variable } & \multicolumn{2}{|c|}{ Passed } & \multicolumn{2}{|c|}{ Grade } \\
\hline & & Sunk-cost prone & Others & Sunk-cost prone & Others \\
\hline \multirow[t]{3}{*}{ (1) } & Free & $0.03(0.12)$ & $0.16(0.12)$ & $-0.03(0.43)$ & $0.54(0.46)$ \\
\hline & LD & $0.18(0.11)$ & $0.06(0.09)$ & $-0.14(0.37)$ & $-0.16(0.40)$ \\
\hline & $\mathrm{SD}$ & $0.01(0.11)$ & $-0.01(0.11)$ & $-0.14(0.41)$ & $0.20(0.45)$ \\
\hline (2) & Free & $-0.04(0.09)$ & $0.14(0.09)$ & $0.07(0.39)$ & $0.53(0.33)$ \\
\hline (3) & Free I LD & $0.10(0.08)$ & $0.11(0.07)$ & $-0.00(0.33)$ & $0.06(0.25)$ \\
\hline (4) & Free | LD | SD & $0.07(0.09)$ & $0.07(0.09)$ & $-0.10(0.31)$ & $0.18(0.38)$ \\
\hline (5) & Discount & $0.09(0.09)$ & $0.13(0.08)$ & $-0.01(0.39)$ & $0.15(0.31)$ \\
\hline \multicolumn{2}{|c|}{$\begin{array}{l}\text { Mean dependent variable } \\
\text { full price treatment }\end{array}$} & 0.45 & 0.38 & 5.7 & 5.2 \\
\hline \multicolumn{2}{|c|}{ Control variables } & \multicolumn{2}{|c|}{ yes } & \multicolumn{2}{|c|}{ yes } \\
\hline \multicolumn{2}{|c|}{ Observations } & \multicolumn{2}{|c|}{295} & \multicolumn{2}{|c|}{266} \\
\hline
\end{tabular}

Table 5. Characterizing sunk-cost-prone students

\begin{tabular}{lccc}
\hline Variable & \multicolumn{3}{c}{ Sunk-cost prone } \\
\hline Female & $0.06(0.06)$ & $-0.00(0.07)$ & $-0.03(0.07)$ \\
Age & $-0.02(0.01)^{* *}$ & $-0.02(0.01)$ & $-0.02(0.01)$ \\
Monthly income (in euros) & & $-0.00(0.00)$ & $-0.00(0.00)$ \\
Economics or Business student & $-0.15(0.07)^{* *}$ & $-0.18(0.07)^{* *}$ \\
Time spend on study (per week) & & $0.00(0.00)$ \\
First attempt for exam & & $-0.09(0.06)$ \\
Max. willingness to pay (fraction of price) & & & $-0.25(0.08)^{* *}$ \\
Predicted prob. passing without tutorial & & & $-0.16(0.16)$ \\
Course paid by parents & & & $0.00(0.06)$ \\
\hline R-squared & 0.02 & 0.04 & 0.06 \\
Observations & 295 & 295 & 295 \\
\hline
\end{tabular}

Note: This table reports results from an OLS regression of the sunk-cost-prone indicator on students background characteristics. Standard errors are in parentheses. $* * *, * *, *$ - estimates significantly different from zero at $1 \%, 5 \%$ and $10 \%$ level. 
in the opposite direction of the sunk-cost effect and may thus possibly explain why we find no support for a sunk-cost effect in the full sample.

To examine this possibility we estimated treatment effects for students who are less likely to be affected by an income effect. We define such students in two ways. First, as students who did not pay for the course themselves but whose parents paid for the course. We asked students whether they paid for the tutorial course from their regular income or whether they received extra money to pay for the tutorial course from their parents. ${ }^{10}$ Second, we take students with monthly income above the median monthly income in our sample (Ashraf et al., 2010 use the same approach).

We re-estimated our models including interaction terms of treatment dummies with indicators for paying parents and above median income, respectively. Table 6 reports the results. If income effects hide the presence of a sunk-cost effect in the full sample, we expect to find negative treatment effects for students who did not pay themselves and for students with income above the median. We find no evidence that income effects hide a sunk-cost effects. In fact we find significantly lower attendance when assigned to the Free treatment for students who paid themselves, but not for students whose parents paid, the opposite of the hypothesized income effect. ${ }^{11}$

\section{Conclusion}

Discounts on tuition fees reduce class attendance of sunk-cost-prone students, which are about $45 \%$ of our sample of university students. When these students do not pay for the course, their attendance rate is 11 percentage points lower than when paying the full price. The course attendance of students who are not sunk-cost prone, is not affected by discounts. To identify sunk-cost-prone students, we followed Ashraf et al. (2010) and used a set of hypothetical questions.

Our results contrast with the findings of Ashraf et al. (2010) and Cohen and Dupas (2010),

\footnotetext{
${ }^{10} \mathrm{We}$ phrase the question like this since most students in the Netherlands receive some study allowance from their parents. We believe the relevant margin is whether students receive extra money, earmarked for the tutoring course. Paying the course from the general study allowance implies a reduction of their disposable income whereas receiving extra money for the course does not.

${ }^{11} \mathrm{Next}$ to income effects, another potential contaminating factor is that students may perceive a lower price as a signal of lower quality. We believe that the procedure of letting students draw a closed envelope guarantees that students will think that the quality of the course is unrelated to the transaction price they paid. Consistent with this we find no impact of the treatment indicators on students' appreciation of the courses (results not reported). Ashraf et al. (2010) conduct a similar test when they use information from their follow-up survey about respondents' perception of product quality (p.2402).
} 


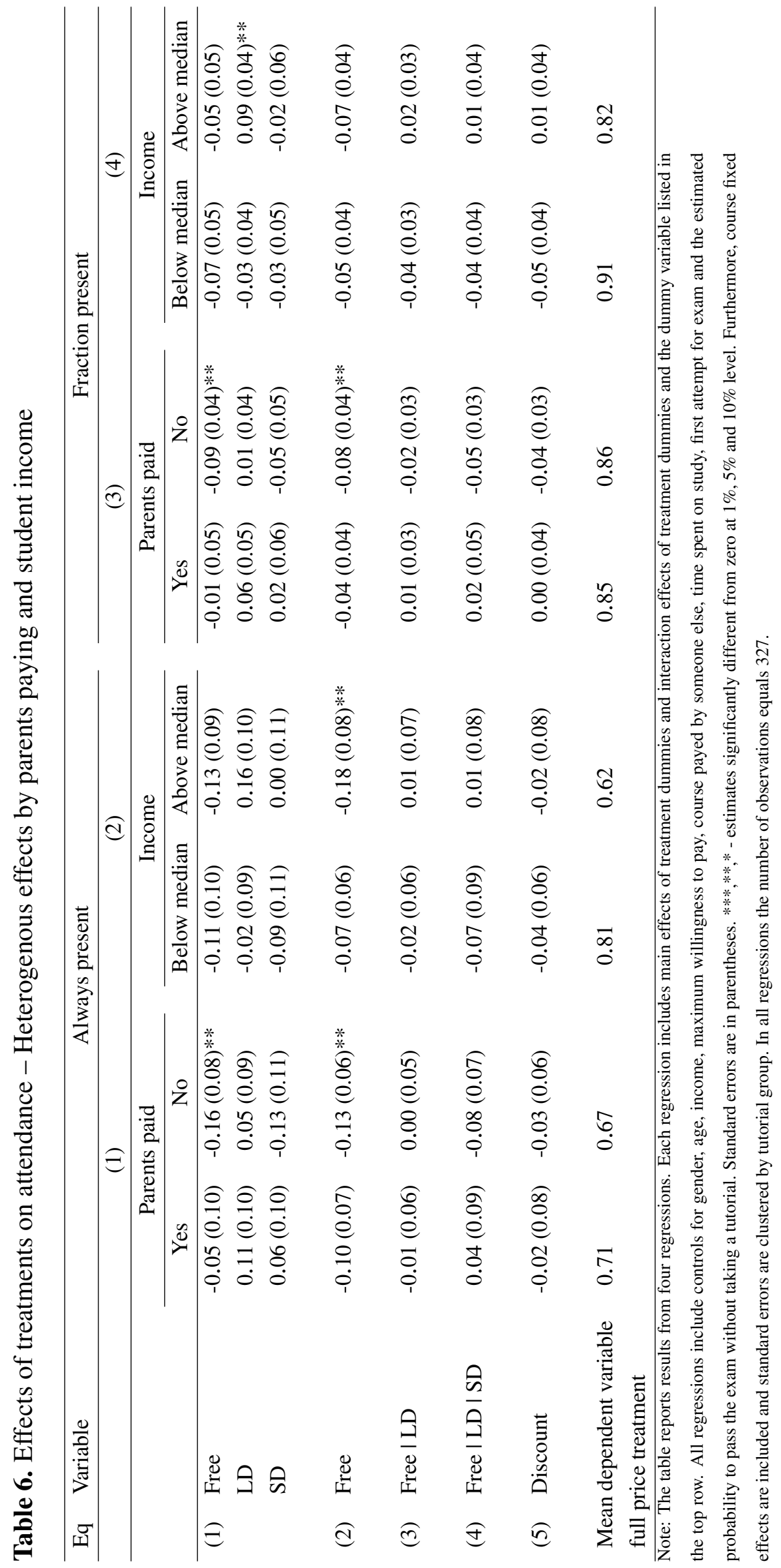


which both fail to find evidence for a sunk-cost effect. Ashraf et al. (2010) do not even find such effects for individuals who are classified as sunk-cost prone. We think that the most plausible explanation for the difference in findings is the sizes of the full price and of the discounts. In the studies of Ashraf et al. (2010) and Cohen and Dupas (2010) the discounts are fractions of dollars, while in our study these range from $€ 10$ to $€ 75$. Rodrik (2009) already argued that the small size of the discounts made it unlikely that Cohen and Dupas (2010) would have found a sunk-cost bias. Too small price differences would also explain why Phillips et al. (1991) and Friedman et al. (2007) find, at best, weak support for the sunkcost effect in their laboratory experiments.

The importance of a substantial discount is supported by Hidalgo et al. (2013) who find that school attendance of primary school students in Ecuador declines when they receive a free school uniform on which families usually spend around $€ 25$. Another difference between the studies of Ashraf et al. (2010) and Cohen and Dupas (2010) on the one hand and our study and Hidalgo et al. (2013) on the other hand is, of course, that the first two examine sunk-cost effects in the context of health products, while the latter two pertain to an education setting. There is, however, no obvious reason why sunk-cost effects would be more prevalent in an education context than in a health context.

In our study we focus on university students who voluntarily signed up for extra-curricular tutorial sessions. While our results do not prove that reduced tuition reduces attendance for (a large subset of) the wider population of university students in regular classes in the Netherlands or elsewhere, it suggests that it does. There are serious concerns about the low effort that university students in the Netherlands (and elsewhere) devote to their studies. To increase study effort, it may be considered to reduce the education subsidies that keep tuition fees low. This can possibly be done in combination with increased financial aid to students to keep university education accessible.

\section{References}

Arkes, H. R. and Blumer, C. (1985). The psychology of sunk cost. Organizational Behavior and Human Decision Processes, 35(1):124-140.

Ashraf, N., Berry, J., and Shapiro, J. M. (2010). Can higher prices stimulate product use? Evidence from a field experiment in Zambia. American Economic Review, 100(5):23832413. 
Cohen, J. and Dupas, P. (2010). Free distribution or cost-sharing? Evidence from a randomized malaria prevention experiment. Quarterly Journal of Economics, 125(1):1-45.

Dynarski, S. M. (2003). Does aid matter? Measuring the effect of student aid on college attendance and completion. American Economic Review, 93(1):279-288.

Friedman, D., Pommerenke, K., Lukose, R., Milam, G., and Huberman, B. (2007). Searching for the sunk cost fallacy. Experimental Economics, 10(1):79-104.

Garland, H. and Newport, S. (1991). Effects of absolute and relative sunk costs on the decision to persist with a course of action. Organizational Behavior and Human Decision Processes, 48(1):55-69.

Gneezy, U. and List, J. A. (2006). Putting behavioral economics to work: Testing for gift exchange in labor markets using Peld experiments. Econometrica, 74(5):1365-1384.

Hidalgo, D., Onofa, M., Oosterbeek, H., and Ponce, J. (2013). Can provision of free school uniforms harm attendance? Evidence from Ecuador. Journal of Development Economics, 103:43-51.

Kane, T. J. (2003). A quasi-experimental estimate of the impact of financial aid on collegegoing. Working Paper 9703, National Bureau of Economic Research.

Leuven, E., Oosterbeek, H., Sonnemans, J., and van der Klaauw, B. (2011). Incentives versus sorting in tournaments: Evidence from a field experiment. Journal of Labor Economics, 29(3):637-658.

Meyer, D. J. (1993). First price auctions with entry: An experimental investigation. Quarterly Review of Economics and Finance, 33(2):107-122.

Offerman, T. and Potters, J. (2006). Does auctioning of entry licences induce collusion? An experimental study. Review of Economic Studies, 73(3):769-791.

Phillips, O. R., Battalio, R. C., and Kogut, C. A. (1991). Sunk and opportunity costs in valuation and bidding. Southern Economic Journal, 58(1):112-128.

Rodrik, D. (2009). The new development economics: We shall experiment, but how shall we learn? In Cohen, J. and Easterly, W., editors, What Works in Development? Thinking Big and Thinking Small. Brookings Institution Press, Washington, DC. 
Thaler, R. (1980). Toward a positive theory of consumer choice. Journal of Economic Behavior \& Organization, 1(1):39 - 60 .

Van der Klaauw, W. (2002). Estimating the effect of financial aid offers on college enrollment: A regression-discontinuity approach. International Economic Review, 43(4):12491287. 


\section{A Description of the courses}

Table A1. Courses offered at universities

\begin{tabular}{llccc}
\hline & Study program & Price (in $€$ ) & \# groups & \# students \\
\hline VU University Amsterdam (VU) & & & & \\
Business Mathematics & Economics and Business & 75 & 3 & 34 \\
Financial Accounting and Bookkeeping & Economics and Business & 75 & 2 & 17 \\
Quantitative Business Analysis & Economics and Business & 75 & 1 & 10 \\
Statistics I (premaster) & Economics and Business & 75 & 2 & 21 \\
Statistics II (premaster) & Economics and Business & 75 & 5 & 57 \\
Mathematics (premaster) & Economics and Business & 75 & 3 & 35 \\
Statistics II & Psychology & 60 & 2 & 16 \\
Meten en Diagnostiek II & Psychology & 60 & 2 & 13 \\
Utrecht University (UU) & & & & \\
Methodology and Statistics I & Social Sciences & 65 & 4 & 34 \\
Methodology and Statistics (premaster) & Social Sciences & 65 & 1 & 10 \\
University of Amsterdam (UvA) & & & & \\
Econometrics & Economics and Business & 75 & 2 & 18 \\
Mathematics and Statistics I & Economics and Business & 75 & 4 & 35 \\
University of Groningen (RUG) & & & & \\
Statistics I A (Dutch) & Psychology & 65 & 3 & 27 \\
Statistics I A (English) & Psychology & 65 & 3 & 23 \\
Statistics II part II & Psychology & 65 & 2 & 21 \\
\hline
\end{tabular}




\section{B The questionnaires}

The questionnaires in this appendix assume a price of $€ 65$ and 5 sessions. This was adjusted depending on the tutorial sessions in question.

Pre-treatment questionnaire

Dear student,

We ask you to take part in a study carried out by the VU and the UvA. In this study you have a $1 / 4$ chance to receive the following discounts on the fee of the tutoring course: $€ 0$, $€ 10, € 55$ or $€ 65$ discount. By completely filling out the questionnaire below you participate in the study. Your information will only be used, anonymized, for our research on study behavior. After filling out the questionnaire, or choosing not to, the fee has to be paid and the potential discount will be determined. If you have any questions regarding the study you can ask them at that time.

\section{Personal information}

1. Name: 2. Student number:

3. Phone number: 06-.......

4. Email address: .............

5. Gender: $\square$ Male $\square$ Female

6. Age: ...... years

\section{Education}

7. Since when do you study?

Since $20 \ldots$

8. Home many hours a week do you spend on your studies, on average?

...... hours per week

9. How many hours do you expect to spend on this course, including the hours spend in tutoring courses? 
...... hours per week

10. Why did you choose to follow tutoring courses for this subject?

11. Did you take tutorial courses through [name of the study association] before? If so, for which subject?

Yes for the subject ............ $\square$ No

12. Did you take the exam for this subject before? If so, how often?

Yes,$\ldots \ldots \ldots \ldots \ldots$ time(s) before $\square$ No

13. How many of the 5 classes do you intend to follow?

1 class $\square 2$ classes $\square 3$ classes $\square 4$ classes $\square 5$ classes

14. How large do you estimate the probability that you will pass the exam?

Without taking this tutoring course: .......\%

After following this tutoring course: ....... \%

\section{Background}

15. With which type of math did you graduate high school?

Math A $\square$ Math B $\square$ Math C $\square$ Math D $\square$ Other, i.e. .....

16. With what math grade did you graduate high school (In case of a non-Dutch exam, please translate the grade to a comparable Dutch grade)?

17. Did you receive extra money from your parents to pay for this course or did you pay for it out of your regular income?

From regular income $\square$ Extra contribution of parents $\square$ Other, i.e. ....... 
18. What is your average monthly income (including student aid and contributions from your parents.)?

$€ \ldots \ldots$

19. What is the maximum amount you would be willing to pay for these tutoring courses?

$€ \ldots \ldots$

20. Do you have friends in this tutorial group? If so, what are their names?

Yes

Names friends:

$\square$ No

Post-treatment questionnaire

Name:

Student number:

Teacher:

Course

Day: Time:

In addition to the usual evaluation questions some questions were added for the study of the UvA and the VU in which most of you participated. The answers to this questionnaire will be treated confidentially and anonymous and will only be used for this study.

\section{General:}

The probability I would recommend this tutoring class to a friend is:

(lowest) 12345678910 (highest) 
Booklet:

The quality of the booklet was:

(lowest) 12345678910 (highest)

The booklet covers all subjects in the course:

(lowest) 12345678910 (highest)

All important subjects in the course were covered with enough assignments:

(lowest) 12345678910 (highest)

Teacher:

The teacher was knowledgeable about all important subjects

(lowest) 12345678910 (highest)

The teacher motivated me to try my best

(lowest) 12345678910 (highest)

The teacher was good

(lowest) 12345678910 (highest)

\section{Other participants:}

Other participants were involved and worked hard during the tutoring classes:

(lowest) 12345678910 (highest)

Other participants were well prepared for the tutoring classes:

(lowest) 12345678910 (highest) 


\section{Final evaluation}

In general I assess these tutoring courses with:

(lowest) 12345678910 (highest)

Would you participate in another tutoring course organized by [Name of the study association] in the future? If not, why?

$\square$ Yes $\square$ No, because ..............

\section{Attendance}

How many and which of the tutoring classes did you miss?

Class 1: $\square$ Present $\square$ Partly absent $\square$ Absent

Class 2: $\square$ Present $\square$ Partly absent $\square$ Absent

Class 3: $\square$ Present $\square$ Partly absent $\square$ Absent

Class 4: $\square$ Present $\square$ Partly absent $\square$ Absent

Class 5: $\square$ Present $\square$ Partly absent $\square$ Absent

If you missed 1 or more classes, what were the reasons for your absence (multiple answers possible)

$\square$ I was ill $\square$ Something else intervened $\square$ I didn't think the class would be useful Other, which is ........

\section{Course}

How many hours did you spent on this course, including the hours spent in tutoring courses ...... hours per week

How large do you estimate the probability that you will pass the exam? ..........\% 


\section{Discount}

Participants in this tutoring course were able to get a discount. The size of the discount was randomly determined. How large was the discount you received?

$€ \ldots \ldots$

In case you got a discount, what did you do with the money?

I gave it back to my parents

I added it to my regular income

I spent it on something special, which is $\ldots \ldots \ldots \ldots$.

$\square$ Other, which is $\ldots \ldots \ldots \ldots \ldots \ldots$

I didn't get a discount

What did you think of the fact that people could get a discount?

\section{Background}

Indicate for each of the following statements the extent to which you agree with it.

On the whole, I am satisfied with myself.

(completely disagree) 1234567 (completely agree)

I certainly feel useless at times.

(completely disagree) 1234567 (completely agree)

I prefer to something that challenges my thinking skills over something that doesn't require me to think.

(completely disagree) 1234567 (completely agree)

I trust my initial hunches. 
(completely disagree) 1234567 (completely agree)

Suppose you bought a bottle of juice for $€ 2$,-. When you start to drink it, you realize you don't really like the taste.

Would you finish drinking it? $\square$ Yes $\square$ No

Now suppose you bought exactly the same bottle of juice for $€ 5$,-. When you start to drink it, you realize you don't really like the taste.

Would you finish drinking it? $\square$ Yes $\square$ No

Now suppose you bought exactly the same bottle of juice for $€ 1$,-. When you start to drink it, you realize you don't really like the taste.

Would you finish drinking it? $\square$ Yes $\square$ No

General remarks about the tutoring course 